\title{
Bronchocele: Two Cases
}

\author{
Gulfidan Cakmak ${ }^{\mathrm{a}, \mathrm{d}}$, Nurdan Gockun ${ }^{\mathrm{b}}$, Emre Evren ${ }^{\mathrm{b}}$, \\ Zuhal Aydan Saglam ${ }^{c}$
}

\begin{abstract}
A bronchocele (bronchial mucocele) results from the mucoid impaction and dilatation of the proximal bronchus caused by congenital bronchial atresia (CBA) or bronchial obstruction. Bronchocele must be considered in the differential diagnosis of radiologic pathologies.
\end{abstract}

Keywords: Congenital bronchial atresia; Bronchocele; Congenital pulmonary disease

\section{Introduction}

Bronchial atresia is a rare variety. In this article we aimed to remind bronchocele clinically and radiologically in differential diagnosis by reporting two patients with bronchocele of which one presented with infection and the other was incidentally found.

\section{Case Report}

\section{Case 1}

An asymptomatic 34-year old woman applied for a health certificate which was required for job application. Her physical examination revealed no pathology. She wasn't smoking

Manuscript accepted for publication July 5, 2013

\footnotetext{
${ }^{a}$ Haseki Training and Research Hospital, Chest Disease, Istanbul, Turkey

${ }^{b}$ Haseki Training and Research Hospital, Radiology, Istanbul, Turkey

${ }^{\mathrm{c}}$ Department of Family Medicine, Goztepe Training and Research Hospital, Istanbul Medeniyet University, Turkey

${ }^{\mathrm{d} C}$ Corresponding author: Gulfidan Cakmak, Merkezefendi mh Topkapi merkezevleri A 4 blok D 10 Zeytinburnu, Istanbul, Turkey.

Email: gulfidan70@gmail.com
}

doi: http://dx.doi.org/10.4021/jmc1364w and not taking any medicine for any disease either. Her chest radiography had been taken several times so far, yet she was informed that each of them was normal (Fig. 1). Computed thorax tomography was performed according to the findings at chest $\mathrm{x}$-ray(Fig. 2, 3).

\section{Case 2}

A 30-year old woman had a three-week history of cough, fever and chest pain. The clinical findings lead to a pulmonary infection so antibiotherapy was started. The electrocardiogram was normal. The symptoms slowed down but did not cease so the patient was referred to a chest disease spe-

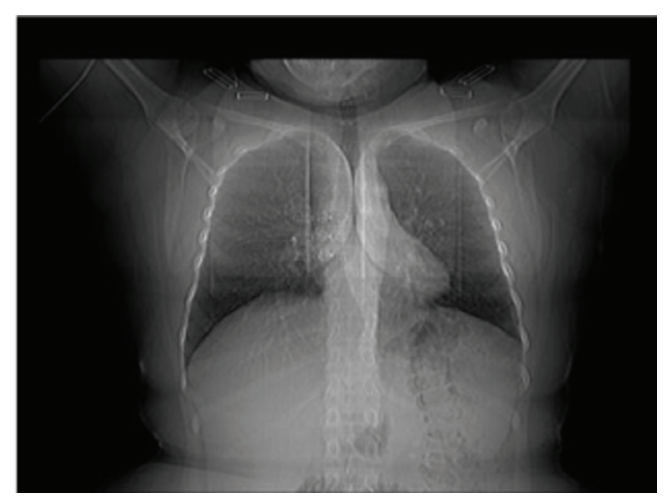

Figure 1. Scanogram of case 1.

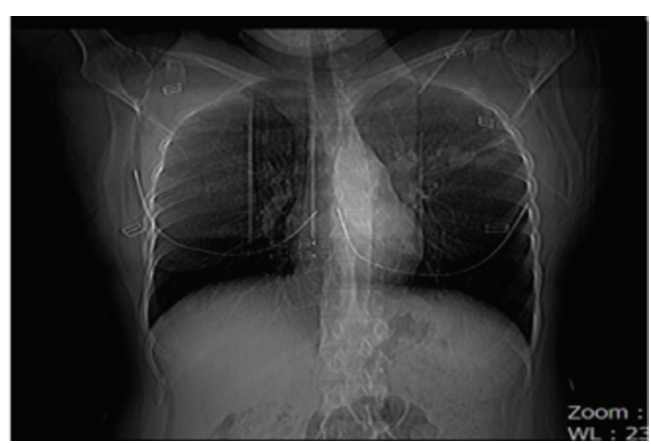

Figure 2. Scanogram of case 2. 


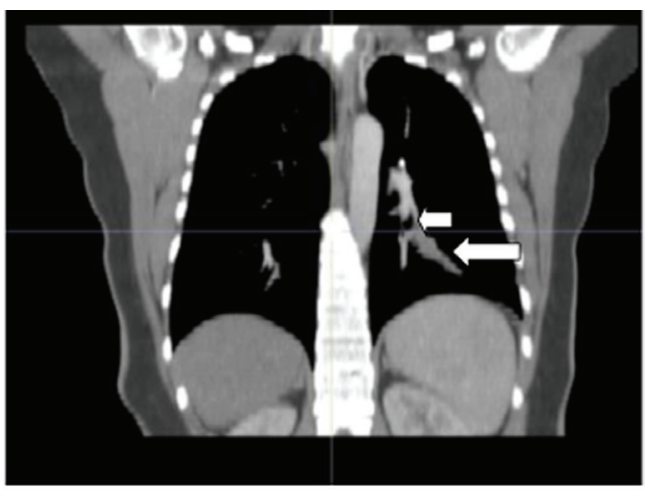

Figure 3. The image with Minimum Intensity Projection technique at coronal mediastinal window of case 1 . Short arrow at left: lower bronchial lobe; long arrow: atresic bronchus filled with mucus.

cialist. Her physical examination was unremarkable except a few rales at the left hemithorax. Her white blood count was $8,800 / \mathrm{mm}^{3}$, erythrocyte sedimentation rate: $15 \mathrm{~mm} /$ hour and C-reactive protein was: $0.9 \mathrm{mg} / \mathrm{dL}$. Computed tomography was performed on the basis of the opacity seen on posterioanterior chest graphy (Fig. 4).

Chest computed tomography was performed from apical to basale with a 64-detector row CT scanner (Brilliance, Philips Healthcare) at supine position and inspirium. Parameters for helical scanning were: tube voltage, $120 \mathrm{kV}$; tube current threshold, $300 \mathrm{mAs}$; rotation time, $0.5 \mathrm{sec} / \mathrm{rot}$; collimation, $64 \times 0.625 \mathrm{~mm}$; beam pitch, $0.64-1.06$; reconstructed section thickness, $1.0 \mathrm{~mm}$. CT angiography was done using a non-ionic iodinated contrast media of $35 \mathrm{~mL}$ injected through the antecubital vein at $5 \mathrm{~mL} / \mathrm{second}$ rate (Fig. 5, 6).

High-resolution three-dimensional volume renderingmagnetic resonance technique (3-D VR) was conducted when the images were suggestive of bronchocele. The assessments were made with axial reconstruction of $1 \mathrm{~mm}$ and $5 \mathrm{~mm}$ at reformats obtained at coronal and sagittal planes using volume rendered 3-D imaging and $5 \mathrm{~mm}$ Minimum

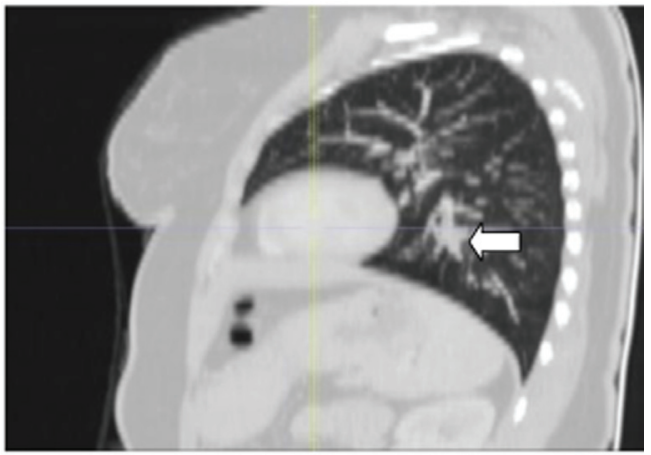

Figure 4. The image with Minimum Intensity Projection technique at sagittal parenchimal window of case 1 . The arrow shows the atresic bronchus filled with mucus.

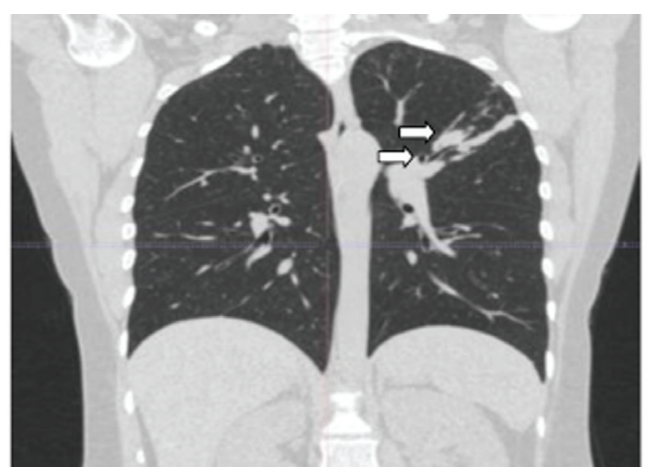

Figure 5. The image with Minimum Intensity Projection technique at coronal parenchimal window of case 2. Left upper arrow: atresic bronchus filled with mucus; left lower arrow: upper apicoposterior segmental bronchus.

Intensite Projeksiyon (MIP) imaging techniques $[1,2]$.

MIP is a data visualization method that enables detection of highly intense structures and doesn't give information about the depth of the image. At minimum intensity projection (Min IP) volume rendering technique, the images get information from each voxel. Min IP, as a computed tomography $(\mathrm{CT})$ volumetric rendering technique provides added diagnostic capabilities as well as help better understanding three dimensional relationships of anatomic structures and determining the appropriate surgical approach in case [2].

It is important to assess the case with axially reconstructed images. Volume rendering may be internally or externally performed and it gives important information about the trachea-bronchial tree as detailed as bronchoscopy $[1,3]$.

So it is granted as a non invasive method in patients who can not tolerate bronchoscopy or refuse to have it done [3,4]. According to all of these evaluations bronchocele related to bronchial atresia was diagnosed radiologically. VR imaging of cases 1 and 2 are shown at Figures 7 and 8.

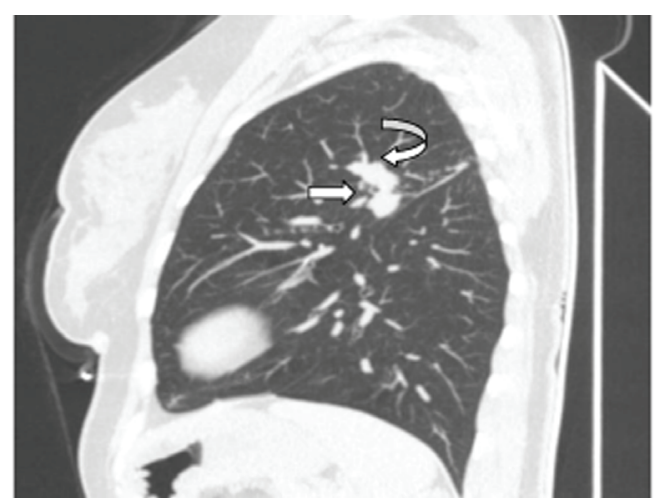

Figure 6. The image with Minimum Intensity Projection technique at sagittal parenchimal window of case 2. Right arrow: the upper bronchus; left arrow: atresic bronchus filled with mucus. 


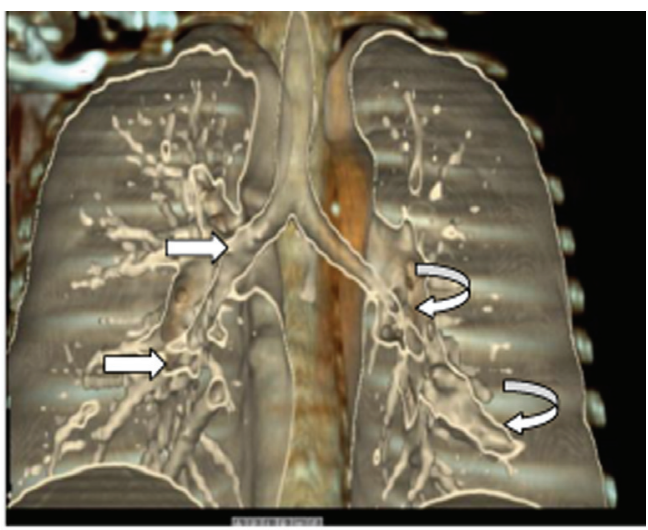

Figure 7. Coronal VR imaging of case 1. Right upper arrow: right main bronchus; right lower arrow: bronchus of lower lobe. Curved left arrows, upper: bronchus of lower lobe; lower: atresic bronchus filled with mucus.

\section{Discussion}

Bronchocele is first defined at 1800's. CBA is the most common reason of bronchocele and. It is a cystic formation caused by mucus impaction and dilatation at the proximal of obstructed or atresic bronchiol [2-4]. Congenital atresia, scatricial shrinkage of bronchial lumen, a foreign object or neoplasms may cause the obstruction. Nevertheless bronchial atresia is the most common reason and first defined at 1949 [1]. Although the obstruction or atresia may cause atelectasis at the lober bronchus, it may not result with volume depletion at segmental or subsegmental bronchioles $[1,5]$. Since we could not demonstrate any massive lesion, a foreign object or fibrotic sequel band which may cause the obstruction in none of our cases, bronchial atresia was considered to be the main reason of the obstruction. Bronchocele cases in literature are generally in association with an obstruction caused by a neoplasm $[6,7]$.

Bronchial atresia is a rare variety of chest anomaly. It generally results from a localized defect in normal bronchopulmonary embryogenesis $[5,8]$. The development of lungparenchyme is generally normal [9]. It has a male predominance. The estimated prevalence is 1.2 cases per 100,000 males [10]. The patients are generally asymptomatic and the disease is diagnosed coincidentally at the second or third decades.

The left upper lobe involvement is $64 \%$ while left lower lobe is $14 \%$ involved [9]. It is commonly demonstrated at a single segmential bronchiol, yet multiple segmential atresias are also reported $[1,6]$. Our cases were diagnosed at their thirties.Raza and Aronberg's cases were at their sixties. Bronchial atresia was at the left lower lobe in our first case while it was at the left upper lobe in the second one. In Raza, Yoon, and Aronberg's cases bronchoceles were at the right upper lobe and lingula, in Gibson's case it was at the left upper lobe similar to our case.

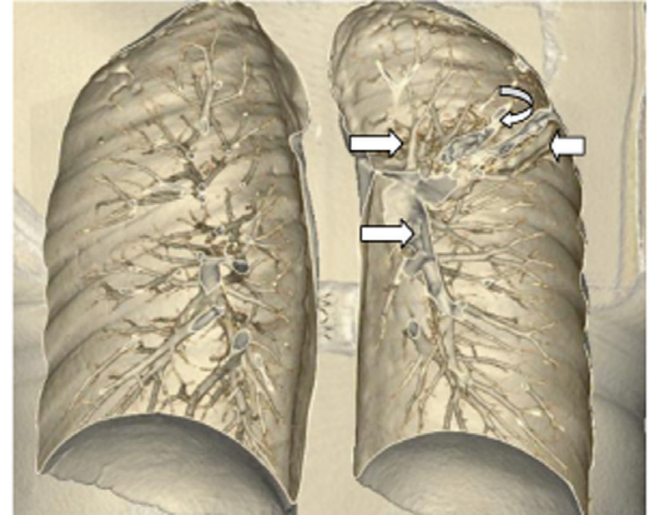

Figure 8. VR image of case 2. Right upper arrow: upper lobe bronchus; right lower arrow: lower lobe bronchus. Left upper arrow: atresic bronchus filled with mucus; left lower arrow: infiltration limited with major fissura.

Bronchocele is diagnosed radiologically or/and by bronchoscopy. Radiologically hyperinflation is reported commonly in the affected side as well as collapse at the affected lobe and mass image of the mucocele. Calcification may also be reported $[5,11]$. In our first case, there was only oscultative findings. In the second one radiologic infiltration was recorded. In differential diagnosis of cystic lesions of lungs; congenital abnormalities (pulmonary sequestration, bronchogenic cyst and bronchocele), tumoral masses (primary pulmonary mucinous adenocarcinosis or pulmonary metastasis of it) should be necessarily kept in mind. Bronchoscopically, blind ending may be demonstrated at the atresic bronchus yet it may be normal as well [10]. Bronchoscopy is also recommended for patients with bronchial atresia in literature in order to exclude other possible pathologies $[4,12,13]$. We performed bronchoscopy to the case who had findings of infection. The result was normal. The other patient refused to have bronchoscopy. On the basis of these information we diagnosed our patients with thorax CT.

Although it may be asymptomatic, dyspnea, recurrent infections and cough, fever and hemoptysis may be recorded. It may rarely cause pneumothorax [8]. Hyperinflation of the obstructed lung segment and check valve mechanism is held responsible $[6,11]$. It may be associated with congenital cystic adenomatoid malformation and pectus excavatum $[9$, $14,15]$.

In conclusion, bronchocele is benign and asymptomatic and may be diagnosed radiologically. Bronchoscopy may be done to exclude associating pathologies. Nevertheless an obstructing tumoral mass should be kept in mind in case an obstruction is determined.

\section{References}

1. Achenbach S, Giesler T, Ropers D, Ulzheimer S, Derlien 
H, Schulte C, Wenkel E, et al. Detection of coronary artery stenoses by contrast-enhanced, retrospectively electrocardiographically-gated, multislice spiral computed tomography. Circulation. 2001;103(21):2535-2538.

2. Gerber BL, Coche E, Pasquet A, Ketelslegers E, Vancraeynest D, Grandin C, Van Beers BE, et al. Coronary artery stenosis: direct comparison of four-section multidetector row $\mathrm{CT}$ and 3D navigator MR imaging for detection--initial results. Radiology. 2005;234(1):98-108.

3. Sakarya ME, Ceran S, Koç O, Ozbek O,KarabekmezLG, Odev K. Bronchocele: DemonstrationBy 3D Volume Rendering Imaging with Multidetector Computed Tomography: Case Report. Turkiye Klinikleri J Med Sci. 2011;31(1):251-255. (in Turkish)

4. Laroia AT, Thompson BH, Laroia ST, van Beek E, Jr. Modern imaging of the tracheo-bronchial tree. World J Radiol. 2010;2(7):237-248.

5. Gipson MG, Cummings KW, Hurth KM. Bronchial atresia. Radiographics. 2009;29(5):1531-1535.

6. Aronberg DJ, Sagel SS, Jost RG, Levitt RG. Oat cell carcinoma manifesting as a bronchocele. AJR Am J Roentgenol. 1979;132(1):23-25.

7. Raza SA, Alexakis C, Creagh M, Lawrence DR, Wood M. Primary pulmonary mucinous cystadenocarcinoma presenting as a complex bronchocele: a case report. J Med Case Rep. 2009;3:8581.

8. Yoon YH, Son KH, Kim JT, Baek WK, Kim KH, Lee
KH, Han HS. Bronchial atresia associated with spontaneous pneumothorax: report of a case. J Korean Med Sci. 2004;19(1):142-144.

9. Cappeliez S, Lenoir S, Validire P, Gossot D. Totally endoscopic lobectomy and segmentectomy for congenital bronchial atresia. Eur J Cardiothorac Surg. 2009;36(1):222-224.

10. Psathakis K, Eleftheriou D, Boulas P, Mermigkis C, Tsintiris K. Congenital bronchial atresia presenting as a cavitary lesion on chest radiography: a case report. Cases J. 2009;2(1):17.

11. Wang Y, Dai W, Sun Y, Chu X, Yang B, Zhao M. Congenital bronchial atresia: diagnosis and treatment. Int $\mathrm{J}$ Med Sci. 2012;9(3):207-212.

12. Ward S, Morcos SK. Congenital bronchial atresia--presentation of three cases and a pictorial review. Clin Radiol. 1999;54(3):144-148.

13. Daoud B, Moncada R, Ali J. Lung mass in a smoker. Chest. 2001;119(3):947-949.

14. Discioscio V, Feraco P, Bazzocchi A, Femia R, Romeo C, Fasano L, Pacilli AM, et al. Congenital cystic adenomatoid malformation of the lung associated with bronchial atresia involving a different lobe in an adult patient: a case report. J Med Case Rep. 2010;4:164.

15. Shepherd FJ. III. Some Remarks on the Symptoms of Bronchocele and the Results of Operative Treatment. Ann Surg. 1899;30(5):564-570. 